ISSN = 1980-993X - doi:10.4136/1980-993X
www.ambi-agua.net
E-mail: ambi-agua@agro.unitau.br
Tel.: (12) 3625-4212

\title{
Biomonitoramento do ar com Tradescantia pallida (Rose) D. R. Hunt var purpurea Boom (Commelinaceae)
}

\author{
(http://dx.doi.org/10.4136/ambi-agua.982)
}

\author{
Mateus Cabral Vasconcellos Teixeira; Agnes Barbério \\ Departamento de Biologia, Instituto Básico de Biociências \\ Universidade de Taubaté, Taubaté, SP, \\ e-mail: agnesbarberio@yahoo.com.br, mateuscabral1989@bol.com.br
}

\section{RESUMO}

O crescimento populacional e o conforto gerado pelo progresso têm contribuído amplamente para o aumento da poluição do ar, fazendo com que o ar de vários centros urbanos apresente cada vez mais substâncias nocivas aos seres vivos. O presente estudo objetivou caracterizar a qualidade do ar no município de Taubaté, Vale do Paraíba-SP utilizando biomonitoramento com Tradescantia pallida (Rose) D. R. Hunt purpurea Boom (Commelinaceae). O estudo foi desenvolvido num período de 10 meses (setembro/2010 a junho/2011) em cinco localidades (Rodovia Presidente Dutra - tráfego veicular intenso; Estiva - área residencial; Parque Aeroporto - área industrial; Campus Bom Conselho - centro da cidade com alto fluxo veicular e Agronomia - área rural. Foram realizadas semanalmente coletas das inflorescências jovens das plantas expostas. Após a coleta, as inflorescências foram fixadas em solução de etanol/ácido acético glacial $(3: 1)$ por $24 \mathrm{~h}$, transferidas para solução de etanol $70 \%$ e conservadas sob refrigeração. As mesmas foram submetidas à coloração com carmim acético e quantificado o número de micronúcleos em aproximadamente 300 tétrades para cada inflorescência, sendo confeccionadas lâminas com 10 inflorescências/semana para cada ponto estudado. As médias e desvios padrões foram: Dutra $(2,24 \pm 1,58)$, Estiva $(2,07 \pm 1,33)$, Parque Aeroporto $(1,47 \pm 1,05)$, Bom Conselho $(1,42 \pm 0,90)$ e Agronomia $(0,82 \pm 0,80)$. Apesar de Taubaté ser uma região em crescimento urbano, os dados revelaram que o ar da cidade apresentou boa qualidade. Manter esse equilíbrio é fundamental, requer esforços e aferição periódica, neste sentido, o biomonitoramento é um método rápido, barato e eficiente.

Palavras-chave: Tradescantia pallida, micronúcleo, poluição atmosférica.

\section{Biomonitoring of the air with Tradescantia pallida (Rose) D. R. Hunt var purpurea Boom (Commelinaceae)}

\begin{abstract}
The population growth and the comfort generated by progress have greatly contributed with the increase in the air pollution, making the air in several urban centers polluted by substances that are harmful to human being. This study characterized the air quality in the city of Taubaté, Vale do Paraíba-SP using biomonitoring with Tradescantia pallida (Rose) D. R. Hunt purpurea Boom (Commelinaceae). The study was developed in a period of 10 months (September/2010 to June/2011) in five locations (Rodovia Presidente Dutra - heavy vehicle traffic; Estiva - residential area; Parque Aeroporto - industrial area); Campus Bom Conselho - area in the city with heavy vehicle traffic and Agronomy - rural area. Samples were
\end{abstract}


TEIXEIRA, M. C. V.; BARBÉRIO, A. Biomonitoramento do ar com Tradescantia pallida (Rose) D. R. Hunt var purpurea Boom (Commelinaceae). Ambi-Agua, Taubaté, v. 7, n. 3, p. 279-292, 2012. (http://dx.doi.org/10.4136/ambi-agua.982)

collected on a weekly basis from young inflorescences of exposed plants. After the inflorescences were collected, they were fixed in an absolute ethanol-glacial acetic acid (3:1) solution for $24 \mathrm{~h}$, transferred to ethanol $70 \%$ solution and maintained under refrigeration. They were submitted to coloration with acetic carmine and the number of micronucleus was quantified in approximately 300 tetrads for each inflorescence, and slides were prepared with 10 inflorescences/week for each point of study. The average and standard deviations were: Dutra $(2.24 \pm 1.58)$, Estiva $(2.07 \pm 1.33)$, Parque Aeroporto $(1.47 \pm 1.05)$, Bom Conselho $(1.42 \pm 0.90)$ and Agronomy $(0.82 \pm 0.80)$. Although Taubaté area is a region experiencing urban growth, the data revealed that the air in the city has good quality. Maintaining this balance is very important, requires effort and periodic measurements, and, for this, biomonitoring is a fast, cheap and effective method.

Keywords: Tradescantia pallida, micronuclei, air pollution.

\section{INTRODUÇÃO}

O crescimento populacional e o conforto gerado pelo progresso têm contribuído amplamente para o aumento da poluição atmosférica, fazendo com que o ar de vários centros urbanos apresente cada vez mais substâncias nocivas aos seres vivos. Inúmeras são as substâncias orgânicas e inorgânicas com características aneugênicas (aquelas que podem interferir no fuso mitótico) e clastogênicas (que causam quebras cromossômicas), como benzenos, hidrocarbonetos aromáticos, materiais particulados e metais pesados (Grant, 1992; Monarca et al., 1999; Silva, 2005; Cetesb, 2006; Marcílio e Gouveia, 2007; Junior et al., 2008; Mariani et al., 2008; Carneiro et al., 2011; Habermann et al., 2011).

Entre os fatores que contribuem para o agravamento da poluição, destaca-se a emissão de gases nocivos pelas descargas de veículos automotores, podendo-se usar a intensidade do tráfego veicular como medida indireta do acúmulo desses poluentes em determinadas regiões (Monarca et al., 1999; Silva, 2005; Junior et al., 2008; Mariani et al., 2008; Yanagi, 2010; Carneiro et al., 2011; Habermann et al., 2011).

Neste contexto, o monitoramento da poluição atmosférica constitui importante ferramenta que auxilia na tomada de decisões, tais como a adoção de medidas de controle, diminuição das substâncias expelidas pelas chaminés de indústrias e controle da frota veicular (Silva, 2005). Biomonitoramento consiste em um método de análise experimental que permite avaliar poluentes em grandes extensões de áreas utilizando organismos vivos, que são denominados bioindicadores (Carneiro, 2004; Mariani et al., 2008). Tem sido uma ferramenta útil e importante para o fornecimento de informações rápidas e seguras sobre as ações dos poluentes na biota, além de promover dados que permitem comparar informações obtidas pelos métodos convencionais de monitoramento do ar atmosférico, como o medidor de partículas atmosféricas $\mathrm{PM}_{10}$ e $\mathrm{PM}_{2,5}$ (Alves et al., 2001; Carneiro, 2004; Oliveira et al., 2005; Mielli, 2008). Os biondicadores reagem ao estresse promovido por substâncias que se acumulam em seus tecidos, ocasionando modificações bioquímicas, fisiológicas e morfológicas (Klumpp et al., 2001; Carneiro, 2004). Entre os organismos mais utilizados como bioindicadores, destacam as plantas superiores que são mais sensíveis à poluição que os animais, portanto, estudos sobre os efeitos dos poluentes nas plantas fornecem subsídios importantes para os programas de controle da poluição do ar (Alves et al., 2001; Carneiro, 2004; Klumpp, 2004; Junior et al., 2008; Mariani et al., 2008). As respostas das plantas bioindicadoras aos poluentes podem ser observadas em níveis microscópicos ou macroscópicos através do aparecimento de cloroses, necroses, queda foliar ou diminuição no seu crescimento (Alves et al., 2001; Saldiva et al., 2002; Junior et al., 2008; Mariani et al., 2008). 
TEIXEIRA, M. C. V.; BARBÉRIO, A. Biomonitoramento do ar com Tradescantia pallida (Rose) D. R. Hunt var purpurea Boom (Commelinaceae). Ambi-Agua, Taubaté, v. 7, n. 3, p. 279-292, 2012. (http://dx.doi.org/10.4136/ambi-agua.982)

Dentre as plantas bioindicadoras destaca-se a Tradescantia pallida (Rose) D. R. Hunt var. purpurea Boom por apresentar fácil adaptação em qualquer ambiente, podendo se desenvolver durante todo o ano, apresentando-se como um instrumento favorável para estudos de biomonitoramento em grandes escalas (Bloching et al., 2000; Majer et al., 2001; SerranoGarcia e Montero-Montoya, 2001; Ramirez e Saldanha, 2002; Savóia, 2007; Lisbôa e Ignotti, 2008). De tamanho relativamente pequeno $(\sim 25 \mathrm{~cm})$, seis pares de grandes cromossomos e disponibilidade durante o ano todo, são características que disseminaram seu uso em estudo citogenéticos (Ma, 1981; Lorenzi e Souza, 2001; Carneiro, 2004; Lisbôa e Ignotti, 2008).

A Tradescantia tem sido utilizada experimentalmente desde os primeiros estudos que relacionavam atividade genética com a ação de compostos e agentes químicos (Ma, 1981, 1983; Grant et al., 1992; Klumpp, 2004). Praticamente todas as partes dessa planta podem compor bioensaios de mutagênese para a detecção e monitoramento da poluição ambiental: flores, pétalas, pêlos estaminais, raiz, microsporos, tubo polínico e material genético (aberrações cromossômicas mitóticas e meióticas, micronúcleos, troca entre cromátides irmãs), (Grant, 1998). Dentre esses ensaios dois são ideais na identificação da poluição atmosférica, o bioensaio de micronúcleos (Trad-MCN) e o de pêlos estaminais (Trad-SH) (Ma, 1981; Grant et al., 1992, Ma et al., 1994). O teste dos micronúcleos com Tradescantia spp. (Trad-MCN) é considerado um dos mais sensíveis e eficientes para a detecção de agentes genotóxicos no ar (Ma, 1981, 1983; Ennever et al., 1988; Rodrigues et al., 1997; Saldiva et al., 2002 Misík et al., 2007; Junior et al., 2008). Este bioensaio se baseia na formação de micronúcleos em células mãe dos grãos de pólen presentes nos botões florais de inflorescências jovens de Tradescantia expostas à poluição ambiental (Ma, 1981; Rodrigues et al., 1997; Klumpp, 2004; Klumpp et al., 2006). Os micronúcleos são estruturas resultantes de cromossomos inteiros ou de fragmentos cromossômicos que se perderam durante a divisão celular, e por isso não são incluídos nos núcleos das células filhas, permanecendo no citoplasma das células interfásicas (Majer et al., 2001; Carrard et al., 2007). Embora os mecanismos de reparo celular sejam eficientes, a sua formação se deve a alterações cromossômicas, muitas vezes ligadas a fatores ambientais (Majer et al., 2001). Neste sentido, a ocorrência tanto de danos estruturais, quanto de aneuploidia, permitem detectar a ação de agentes clastogênicos e aneugênicos (Marcilio e Gouveia, 2007; Junior et al., 2008; Carneiro et al., 2011; Habermann et al., 2011).

As grandes concentrações de poluentes atmosféricos representam um risco eminente para a saúde humana e para o bem estar de outros organismos (Klumpp et al., 2006; Marcílio e Gouveia, 2007). Embora os resultados dessas exposições não sejam completamente conhecidos, diversos estudos epidemiológicos relatam correlações significativas entre diferentes níveis de poluições do ar e seus efeitos agudos, crônicos e deletérios aos organismos, principalmente aos seres humanos (Saldiva et al., 1994, 1995; WHO, 2000, 2005; Branco e Murgel, 2004; Molina e Molina, 2004; Wilson et al., 2004; Cançado et al., 2006; Nascimento et al., 2006; Marcilio e Gouveia, 2007).

Considerando Taubaté uma importante cidade do Vale do Paraíba, situada entre o eixo Rio-São Paulo, o presente estudo objetivou caracterizar a qualidade do ar desta região, utilizando o bioensaio com Tradescantia pallida (Rose) D. R. Hunt var. purpurea Boom (Commelinaceae).

\section{MÉTODO}

Para o estudo foram utilizadas plantas jovens de T. pallida provenientes de um mesmo clone, onde foram cultivadas e propagadas no Campus Ciências Agrárias da Universidade de Taubaté (UNITAU) localizado na Estrada Municipal Dr. José Luis Cembranelli. 
TEIXEIRA, M. C. V.; BARBÉRIO, A. Biomonitoramento do ar com Tradescantia pallida (Rose) D. R. Hunt var purpurea Boom (Commelinaceae). Ambi-Agua, Taubaté, v. 7, n. 3, p. 279-292, 2012. (http://dx.doi.org/10.4136/ambi-agua.982)

O estudo foi realizado no município de Taubaté (23 01' 33” S $45^{\circ} 33^{\prime} 31^{\prime \prime} \mathrm{O}$ ), Vale do Paraíba, São Paulo, durante dez meses (setembro de 2010 a junho de 2011). Taubaté possui área total de $625,9 \mathrm{~km}^{2}$, que abriga uma população de mais de 278.686 habitantes (IBGE, 2010). Apresenta clima tropical com inverno seco, tendo no verão, médias acima de $22{ }^{\circ} \mathrm{C}$ e no inverno $18{ }^{\circ} \mathrm{C}$; a média pluviométrica é de $1.344 \mathrm{~mm} / \mathrm{ano}$. Em sua frota veicular constam mais de 3.115 caminhões, 8.728 caminhonetes, 801 microônibus, 39.462 motos, 816 ônibus, 103.437 automóveis e outros tipos de veículos, totalizando 167.614 veículos (DENATRAN, 2012) e possui aproximadamente 424 indústrias (SEADE, 2012).

Foram monitoradas cinco localidades de acordo com a intensidade de tráfego veicular: 1) Rodovia Presidente Dutra, altura do Km 109 sentido São Paulo, região que apresenta alto fluxo veicular, com diversos tipos de veículos, moradias e indústrias nas proximidades; 2) Campus Bom Conselho (UNITAU), cercado por árvores, prédios e avenidas com intenso fluxo veicular; 3) Campus Ciências Agrárias (UNITAU), localidade distante do centro da cidade cerca de $10 \mathrm{~km}$, com áreas verdes e baixo fluxo de veículos; 4) Escola Municipal Prof. Ernesto de Oliveira Filho, localizada no Bairro Parque Aeroporto, situada em uma área industrial, entretanto aberta, com boa ventilação e baixo fluxo veicular; e 5) Escola Municipal Monsenhor Evaristo Campista Cesar, situada no Bairro Estiva, considerada uma área residencial com elevado fluxo veicular.

Foram colocadas duas floreiras com 30 espécimes de $T$. pallida em cada uma dessas localidades. As floreiras receberam o mesmo substrato e posicionadas no local de melhor ventilação.

As coletas das inflorescências jovens foram realizadas semanalmente nos cinco pontos amostrais, o termo inflorescência refere-se à fase de pré-floração da espécie (botão). Após a coleta as mesmas foram fixadas em solução de etanol/ácido acético glacial (3:1) por $24 \mathrm{~h}$, transferidas para solução de etanol $70 \%$ e mantidas sob refrigeração até o momento da análise. Para a análise citológica foi realizada a contagem de micronúcleos (MCN), onde se procedeu ao esmagamento das anteras e quando verificada a fase de tétrades, as mesmas foram submetidas à coloração com carmim acético, de acordo com o protocolo estabelecido por Ma (1981). Para cada local estudado foram confeccionadas 10 lâminas por semana. As frequências de micronúcleos foram registradas em cada lâmina (número de micronúcleos em 300 tétrades) e expressas em termos de número de micronúcleos por 100 tétrades (Campos Junior e Kerr, 2009). Esta etapa foi desenvolvida no Laboratório de Biologia da Universidade de Taubaté (IBB - UNITAU).

A frequência de micronúcleos foi analisada pelo teste de Kruskal-Wallis e ANOVA um critério, e comparadas entre os diferentes locais de exposição pelo teste de Dunn, $p<0,05$.

\section{RESULTADOS E DISCUSSÃO}

As coletas foram feitas em intervalos semanais no período de dez meses de exposição, abrangendo assim três estações consecutivas: primavera, verão e outono. De acordo com a análise de variância Kruskal-Wallis como pré-teste, houve diferença significativa entre os cinco pontos estudados quando comparados entre si $(K=203,6 ; p=0,001)$. Em uma segunda análise utilizou-se o método de Dunn como pós-teste, demonstrando quais as localidades foram diferentes entre si (Tabela 1).

A dinâmica da poluição demonstrada pela frequência de $\mathrm{MCN}$ nas diferentes localidades sugere o seguinte gradiente de poluição: Dutra > Estiva > Bom Conselho > Parque Aeroporto e Agronomia.

A média da frequência de micronúcleos nas cinco localidades variou de $0,8 \%$ a 2,3\%. Estudo realizado por Savóia (2007) em cinco localidades na cidade de Santo André/SP foram observadas frequências de micronúcleos que variaram de 0,5 a 4,8\%, sendo que o menor valor 
TEIXEIRA, M. C. V.; BARBÉRIO, A. Biomonitoramento do ar com Tradescantia pallida (Rose) D. R. Hunt var purpurea Boom (Commelinaceae). Ambi-Agua, Taubaté, v. 7, n. 3, p. 279-292, 2012. (http://dx.doi.org/10.4136/ambi-agua.982)

foi observado na área controle caracterizada pelo baixo índice de tráfego veicular localizada em área de manancial próximo a um parque. Nos estudos realizados por Guimarães et al. (2000), Alves et al. (2003) e Sant'Anna (2003) em regiões consideradas controles, com baixos níveis de poluição atmosférica, foi observada média de 2,3\% de MCN. Junior et al. (2008) com estudo realizado na cidade de Senhor de Bonfim, Bahia e Mariani et al. (2008) com estudos em São José dos Campos, Vale do Paraíba-SP, também demonstraram que regiões com baixo tráfego veicular apresentaram frequência média baixa de micronúcleos. Neste sentido, os resultados obtidos na presente pesquisa estão de acordo com a literatura pertinente.

Tabela 1. Frequência de micronúcleos em $T$. pallida exposta a cinco localidades na cidade de Taubaté/SP no período de setembro/2010 a junho/2011.

\begin{tabular}{l|cc}
\hline Localidade & Média \pm Desvio Padrão & $\begin{array}{c}\mathbf{N}^{\mathbf{0}} \text { Total de Inflorescências } \\
\text { Analisadas }\end{array}$ \\
\hline Dutra & $2,24 \pm 1,58^{\mathrm{a}}$ & 352 \\
Estiva & $2,07 \pm 1,33^{\mathrm{a}}$ & 253 \\
Bom Conselho & $1,47 \pm 1,05^{\mathrm{ba}}$ & 285 \\
Pq. Aeroporto & $1,42 \pm 0,90^{\mathrm{ba}}$ & 208 \\
Agronomia & $0,82 \pm 0,80^{\mathrm{b}}$ & 373 \\
\hline
\end{tabular}

Nota: Frequências médias indicadas com letras distintas são significativamente diferentes (Kruskal-Wallis, Dunn sendo $p<0,01$ ).

A distribuição temporal para os cinco pontos de coleta pode ser observada na Figura 1.

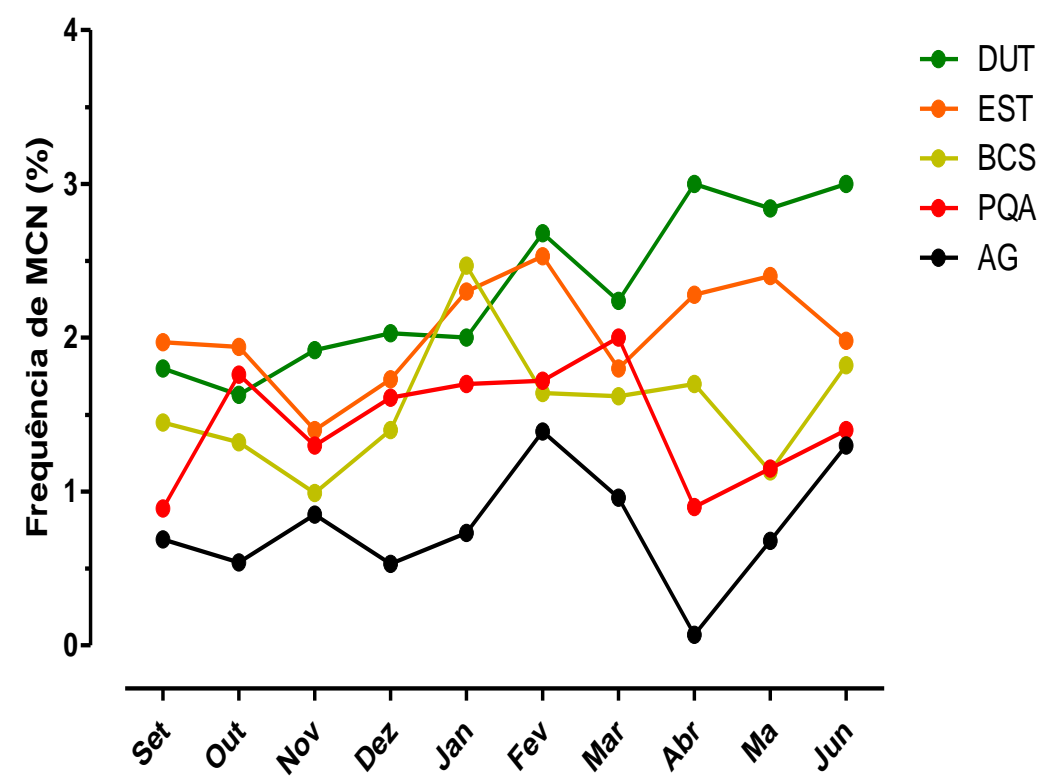

Figura 1. Frequência média de MCN obtidas a partir de inflorescências de $T$. pallida expostas cinco localidades: DUT Dutra, EST - Estiva, BCS - Bom Conselho, PQA - Parque Aeroporto e AG - Agronomia.

Em uma segunda abordagem foram realizadas análises estatísticas para cada ponto comparando os meses entre si. Dutra $(\mathrm{F}=4,183 ; \mathrm{p}<0,001)$, Estiva $(\mathrm{F}=126,8 ; \mathrm{p}<0,001)$, Bom Conselho $(F=3,029 ; p<0,001)$, Parque Aeroporto $(F=4,715 ; p<0,001)$ e Agronomia $(\mathrm{F}=5,753 ; \mathrm{p}<0,001)$. 
TEIXEIRA, M. C. V.; BARBÉRIO, A. Biomonitoramento do ar com Tradescantia pallida (Rose) D. R. Hunt var purpurea Boom (Commelinaceae). Ambi-Agua, Taubaté, v. 7, n. 3, p. 279-292, 2012. (http://dx.doi.org/10.4136/ambi-agua.982)

A frequência de MCN foi mais alta nos meses de abril e junho de 2011 na Dutra, apresentou picos de até 3,00\%, em fevereiro na Estiva com 2,53\%, janeiro com 2,47\% no Bom Conselho, em março no Pq. Aeroporto (2,00\%) e Agronomia 1,39\% e 1,30\% apresentaram os maiores valores nos meses de fevereiro e junho, respectivamente. Isso mostra um comportamento sazonal esperado, com maiores concentrações depois do período chuvoso.

Dutra foi o ponto que apresentou a maior frequência de micronúcleo. Por ser uma importante Rodovia que liga as duas maiores cidades do Brasil, São Paulo e Rio de Janeiro, apresenta alto tráfego veicular, em média 45,5 veículos por minuto, com uma frota variada de veículos, desde carros de passeio, ônibus, entre outros, até caminhões de transporte de carga. Devido a essa grande variedade e intensidade de fluxo de veículos automotores, são liberados diversos poluentes na atmosfera como hidrocarbonetos policíclicos aromáticos, metais pesados, benzenos, cuja atividade genotóxica pode causar danos aos seres vivos. Além do alto tráfego veicular, também existem em suas margens, indústrias de diversos ramos como automobilística, usinagem, alimentícias, etc, que também contribuem com a liberação de diversas substâncias orgânicas e inorgânicas para a atmosfera.

No bairro Estiva, foi registrada a segunda maior frequência de micronúcleo em todo o período estudado. Este resultado se justifica pelo fato da região apresentar alto tráfego veicular com carros de passeios e de transporte coletivo, além de ser cortada pela Estrada do Pinhão, uma importante via que liga a região rural ao centro da cidade; é rodeada por avenidas importantes como Avenida Charles Schnneider, Avenida Vito e Benedito Sergio, trata-se de uma região rodeada por casas, escolas, pouca vegetação, muitos semáforos, fator que promove maior descarga de poluentes, já que quando os veículos "arrancam" eles tendem a emitir uma carga maior de poluentes. Em adição a esses fatores, é uma região desfavorável à dispersão dos poluentes atmosféricos.

Esses dados estão de acordo com os realizados por Monarca et al. (1999) que também observaram maior frequência de micronúcleos em plantas expostas a amostras de ar coletadas em uma rua com intenso tráfego de veículos. Para Guimarães et al. (2000) em estudo realizado na cidade de São Paulo em duas regiões que possuem diversas avenidas com intenso tráfego veicular com diversos tipos de veículos, Congonhas e Cerqueira Cesar, a frequência de MCN observada foi em torno de 5,7\% e 3,9\%, respectivamente.

Prajapati e Tripathi (2008) avaliaram a interferência de indústrias e fluxo veicular em uma cidade na Índia, nos resultados observados a frequência de MCN foi de 3,6\%. Ferreira et al. (2003) relataram associações entre o fluxo veicular e danos genéticos que promoveram mutações em pêlos estaminais de Tradescantia. Valverde e Brandeburgo (2009) também encontraram associações positivas entre o fluxo veicular (movidos por diferentes tipos de combustíveis) e aborto polínico em Tradescantia.

O ponto do Parque Aeroporto seguido de Agronomia, foram os que apresentaram menor frequência de micronúcleo. Ambas as localidades estão distante do centro da cidade, cerca de $10 \mathrm{~km}$ da área urbana, com baixo fluxo veicular, em torno de 3 carros por minuto, apresentam características típicas de locais com baixo índice de poluição atmosférica, sendo ambas as regiões consideradas de "campo aberto". Essas características favorecem a dispersão dos poluentes (Branco e Murgel, 2004). A direção dos ventos é outro fator importante para a dispersão dos poluentes, podendo diminuir a ocorrência de danos genéticos (Alves et al., 2003).

O ponto do Bom Conselho foi a localidade que apresentou média intermediária entre os demais pontos, em desacordo com o esperado. A região está inserida no centro da cidade, rodeada por casas e prédios altos e cortada por uma avenida com médio tráfego veicular (Avenida Tiradentes). É possível que a presença de árvores de grande porte em toda a sua extensão, somando à presença de prédios altos, possa favorecer a formação de correntes e ar dissipando os poluentes liberados pelos veículos que transitam pela região. Contudo, se faz 
TEIXEIRA, M. C. V.; BARBÉRIO, A. Biomonitoramento do ar com Tradescantia pallida (Rose) D. R. Hunt var purpurea Boom (Commelinaceae). Ambi-Agua, Taubaté, v. 7, n. 3, p. 279-292, 2012. (http://dx.doi.org/10.4136/ambi-agua.982)

necessário dar continuidade ao biomonitoramento nessa localidade a fim de verificar a possibilidade de um evento esporádico ou a relação com a dispersão dos poluentes por meio da direção e intensidade dos ventos nesta localidade.

Variações climáticas como precipitação e temperatura tem influência na qualidade da atmosfera (Branco e Murgel, 2004), porém no presente estudo não foi observada nenhuma relação entre as variações climáticas e a frequência de micronúcleos durante o período estudado.

De acordo com os resultados de precipitação no período referente à coleta de inflorescências, os meses de maior pluviosidade foram entre dezembro e abril (Figura 2), entretanto, Dutra e Estiva apresentaram valores altos na frequência de $\mathrm{MCN}$, que se mantiveram nos meses de maio e junho, onde a precipitação foi baixa. Nesse contexto, a precipitação não foi um fator limitante na frequência de MCN. Os valores de precipitação foram obtidos na estação meteorológica da Universidade de Taubaté.

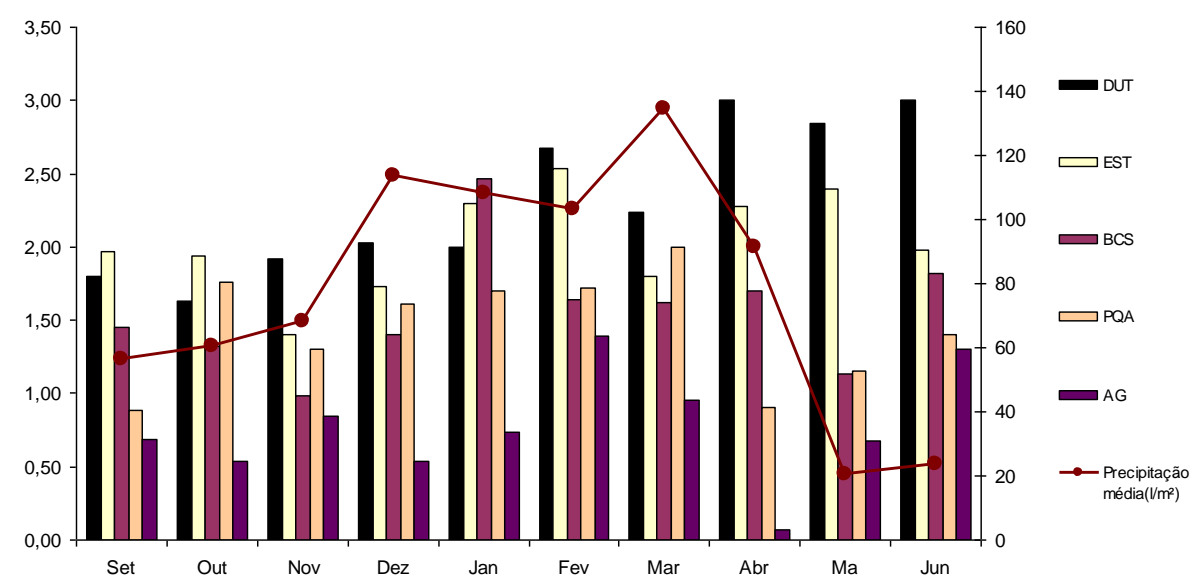

Figura 2. Relação entre a frequência média de $\mathrm{MCN}$ e a precipitação média durante o período de estudo (setembro de 2010 a junho de 2011).

Nota: DUT - Dutra, EST - Estiva, BCS - Bom Conselho, PQA - Parque Aeroporto e AG - Agronomia.

Do mesmo modo, não foi observada associação entre a temperatura e a frequência de MCN nas plantas durante o período de exposição (Figura 3), embora o local Dutra apresente um discreto aumento de MCN nos mês de outono.

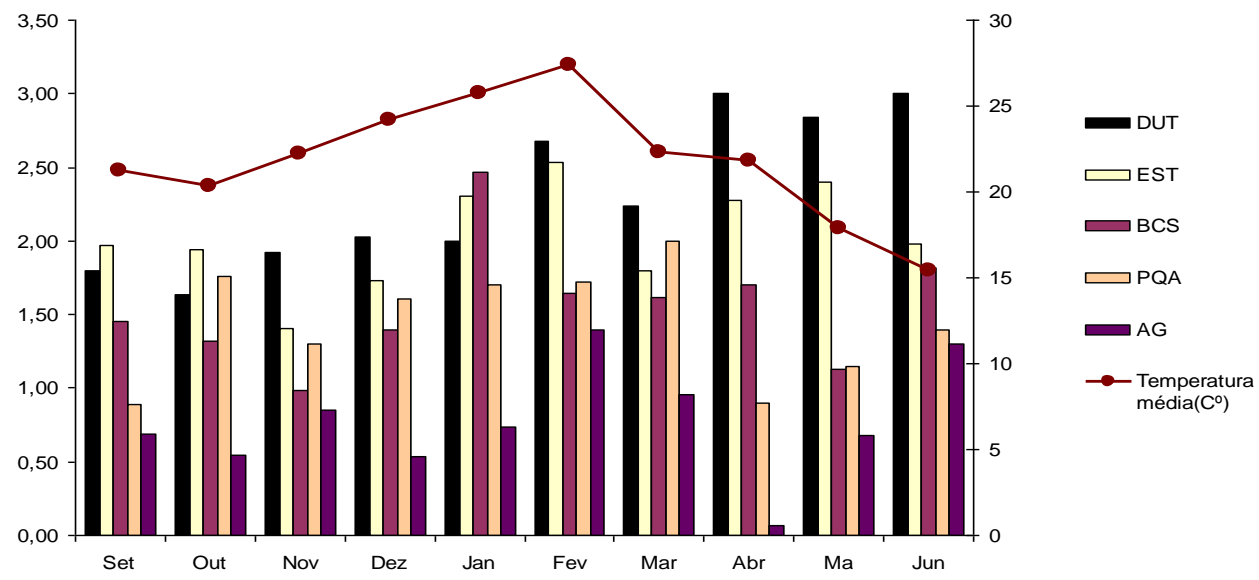

Figura 3. Relação entre a frequência de $\mathrm{MCN}$ e a temperatura durante o período de exposição dos exemplares de T. pallida. DUT - Dutra, EST - Estiva, BCS Bom Conselho, PQA - Parque Aeroporto e AG - Agronomia. 
TEIXEIRA, M. C. V.; BARBÉRIO, A. Biomonitoramento do ar com Tradescantia pallida (Rose) D. R. Hunt var purpurea Boom (Commelinaceae). Ambi-Agua, Taubaté, v. 7, n. 3, p. 279-292, 2012. (http://dx.doi.org/10.4136/ambi-agua.982)

Estudos realizados por Isidori et al. (2003), utilizaram a Tradescantia como ferramenta de monitoramento atmosférico em 17 locais de uma cidade na Itália, em duas estações do ano (verão e inverno), demonstraram que a frequência de MCN foi significantemente mais alta em plantas dos pontos experimentais selecionados, quando comparada à das plantas controles, sendo a frequência de MCN maior no inverno do que no verão. Ferreira et al. (2003) afirmaram que o período chuvoso, é mais propício à dispersão dos poluentes atmosféricos.

Os efeitos da poluição do ar se caracterizam tanto pela alteração de condições consideradas normais como pelo aumento de problemas já existentes; podem ocorrer em nível local, regional e global e podem se manifestar na saúde humana comprometendo o bem estar da população, também afetando os ecossistemas, flora e fauna, podem ainda danificar edificações históricas, exercer interferência sobre as propriedades da atmosfera passando pela redução da visibilidade, alteração da acidez das águas da chuva (chuva ácida), aumento da temperatura da Terra (efeito estufa) e modificação da intensidade da radiação solar (aumento da incidência de radiação ultravioleta, causado pela redução da camada de ozônio), etc.

Em relação à saúde, os efeitos vão desde um simples desconforto respiratório até as doenças crônicas, além do aumento da procura pelo sistema de saúde (centros de saúde, hospitais e pronto socorro).

A qualidade do ar interfere diretamente na vida das pessoas, sendo importante manter controladas as fontes de emissão de poluentes. Bioensaios são eficientes, rápidos e baratos podendo ser uma ferramenta bastante útil na detecção e biomonitoramento desses poluentes. Neste estudo, foi possível atestar a boa qualidade do ar na cidade de Taubaté através do bioensaio TRAD-MCN, de modo que se mantenham análises periódicas para manter este cenário.

Alguns estudos mencionados neste trabalho encontraram níveis de poluição atmosférica considerados significantemente baixos, cuja média de frequência observada variou entre $0,5 \%$ e 2,3\% micronúcleos. Neste estudo, frequências maiores foram observadas em locais com intenso tráfego veicular, corroborando o esperado. Por outro lado, a menor frequência observada foi de $0,8 \%$ micronúcleos. A princípio, uma frequência abaixo de $1 \%$ parece razoável, entretanto, é necessário que se façam outros estudos de modo a abordar uma frequência significantemente baixa obtida em sítio controle nos quais estudos posteriores possam se basear.

A cidade de Taubaté encontra-se em franco desenvolvimento, cenário representado pelo crescimento populacional e industrial a cada ano. Na cidade, a CETESB realiza monitoramento manual para fumaça, que é um tipo de poluente atmosférico originado a partir de processos de combustão da indústria ou de veículos automotores, da poeira na rua, queima de biomassa, entre outros. Seus efeitos na saúde humana são diversos, além de causar danos na vegetação e contaminar a água e o solo (CETEB, 2011). Apesar disso, o biomonitoramento através do bioensaio Trad-MCN é uma ferramenta mais abrangente no sentido biológico e geográfico, no primeiro porque detecta mutação em exemplares expostos in vivo, no segundo, porque esses exemplares podem ser facilmente distribuídos em vários locais permitindo uma maior cobertura de aferição. Além de ser, rápido, barato e eficiente. Diante do exposto, propõe-se que esta metodologia seja utilizada no biomonitoramento da região, em especial Taubaté, como método complementar às análises químicas realizadas pela CETESB.

\section{CONCLUSÃO}

A qualidade do ar atmosférico da cidade de Taubaté encontra-se predominantemente dentro dos padrões de normalidade preconizados. Estudos subsequentes não necessários para delimitar valores de referência em sítios controles de modo que se permitam delimitar uma distância de segurança dos locais onde a poluição atmosférica é intensa. 
TEIXEIRA, M. C. V.; BARBÉRIO, A. Biomonitoramento do ar com Tradescantia pallida (Rose) D. R. Hunt var purpurea Boom (Commelinaceae). Ambi-Agua, Taubaté, v. 7, n. 3, p. 279-292, 2012. (http://dx.doi.org/10.4136/ambi-agua.982)

\section{AGRADECIMENTOS}

Agradecemos à Universidade de Taubaté pelo fomento concedido pela bolsa PIBIC e por disponibilizar espaço, equipamentos e soluções. Também à Profa. Dra. Maria Cecília Barbosa de Toledo pelas sugestões e auxílio nas análises estatísticas.

\section{REFERENCIAS}

ALVES, E. S.; GIUSTI, P. M.; DOMINGOS, M.; SALDIVA, P. H. N.; GUIMARÃES, E. T.; LOBO, D. J. A. Estudo anatômico foliar do clone híbrido 4430 de Tradescantia: alterações decorrentes da poluição aérea urbana. Revista Brasileira Botânica, São Paulo, v. 24, n. 4, p. 561-566, 2001.

ALVES, E. S., PEDROSO, A. N. V., GUIMARÃES, E. T., DOMINGOS, M.; SALDIVA, P. H. N. Biomonitoramento indoor do potencial mutagênico do ar em laboratórios e herbário do Instituto de Botânica por meio do bioensaio Trad-MCN. Hoehnea, São Paulo, v. 30, n. 2, p. 89-94, 2003.

BLOCHING, M.; HOFMANN, A.; LAUTENSCHLÄGER, C. H.; BERGHAUS, A.; GRUMMIT, T. Exfoliative Cytology of Normal Buccal Mucosa to Predict the Relative Risk of Cancer in the Upper Aerodigestive Tract Using the MN-assay. Oral Oncology, Amsterdam, v. 36, n. 6, p. 550-555, 2000.

BRANCO, S. M.; MURGEL, E. Poluição do ar. Série Polêmica. 2 ed., Ed. Moderna, 2004. 112p.

CANÇADO, J. E. D.; BRAGA, A.; PEREIRA, L. A. A.; ARBEX, M. A.; SALDIVA, P. H. N.; SANTOS, U. P. Repercussões clínicas da exposição à poluição atmosférica. Jornal Brasileiro de Pneumologia, Brasília, v. 32, n. 2, p. 5-11, 2006.

CAMPOS JUNIOR, E. O.; KERR, W. E. Teste de micronúcleo com Tradescantia pallida aplicado ao Biomonitoramento da qualidade do ar da cidade de Uberlândia. Horizonte Científico, Uberlândia, v. 3, n. 2, p. 1-18, 2009.

CARNEIRO, R. M. A. Bioindicadores vegetais de poluição atmosférica: uma contribuição para a saúde da comunidade, 2004 Dissertação (Mestrado em Enfermagem em Saúde Pública), Escola de Enfermagem de Ribeirão Preto da Universidade de São Paulo, São Paulo, 2004.

CARNEIRO, M. F. H.; RIBEIRO, F. Q.; FERNANDES-FILHO, F. N.; LOBO, D. J. A.; BARBOSA JR., F.; RHODEN, C. R.; MAUAD, T.; SALDIVA P. H. N.; CARVALHO-OLIVEIRA, R. Pollen abortion rates, nitrogen dioxide by passive diffusive tubes and bioaccumulation in tree barks are effective in the characterization of air pollution. Environmental and Experimental Botany, Oxford, v. 75, n. 2, p. 272-277, 2011.

CARRARD, V. C.; COSTA, C. H.; FERREIRA, L. A.; LAUXEN, I. S.; RADOS, P. V. Teste dos Micronúcleos - Um Biomarcador de Dano Genotóxico em Células Descamadas da Mucosa. Revista da Faculdade de Odontologia de Porto Alegre, Porto Alegre, v. 48, n. 1/3, p. 77-81, 2007. 
TEIXEIRA, M. C. V.; BARBÉRIO, A. Biomonitoramento do ar com Tradescantia pallida (Rose) D. R. Hunt var purpurea Boom (Commelinaceae). Ambi-Agua, Taubaté, v. 7, n. 3, p. 279-292, 2012. (http://dx.doi.org/10.4136/ambi-agua.982)

CETESB Relatório da Qualidade do Ar no Estado de São. In: Companhia de tecnologia de saneamento ambiental. São Paulo, 2006, Disponível em: http://www.cetesb.sp. gov.br/ agua/aguas-superficiais/35-publicacoes-/-relatorios Acesso em: 8 mar. 2011.

DENATRAN - Departamento Nacional de Trânsito. Frota de Veículos - Frota 2012. Disponível em: http://www.denatran.gov.br/frota.htm. Acesso: 07 abr. 2012.

ENNEVER, F. K.; ANDREANO, G.; ROSENKRANZ, H. S. The ability of plant genotoxicity assay to predict carcinogenicity. Mutation Research, Amsterdam, v. 205, n. 1-4, p. 99-105, 1988.

FERREIRA, M. I.; RODRIGUES, G. S.; DOMINGOS, M.; SALDIVA, P. H. N. In situ monitoring of mutagenicity of air pollutants in São Paulo City using Tradescantia-SHM bioassay. Brazilian Archives of Biology and Technology, Curitiba, v. 46, n. 2, p. 253-258, 2003.

GRANT, W. F. Higher Plant Assays for the Detection of Genotoxicity in Air Polluted Environments. Ecosystem Health, New York, v. 4, n. 4, p. 210-229, 1998. http://dx.doi.org/10.1016/S0027-5107(99)00050-0I

GUIMARÃES, E. T.; DOMINGOS, M.; ALVES, E. S.; CALDINI Jr, N.; LOBO, D. J. A.; LICHTENFELS, A. J. F. C.; SALDIVA, P. H. N. Detection of genotoxicity of air pollutants in and around the city of São Paulo (Brazil) with the Tradescantiamicronucleus (Trad-MCM) assay. Environmental and Experimental Botany, Oxford, v. 44, n. 1, p. 1-8, 2000.

HABERMANN, M.; MEDEIROS, A. P. P.; GOUVEIA, N. Tráfego veicular como método de avaliação da exposição à poluição atmosférica nas grandes metrópoles. Revista Brasileira de Epidemiologia, São Paulo, v. 14, n. 1, p. 120-30, 2011.

IBGE - Instituto Brasileiro de Geografia e Estatística. IBGE Cidades - Censo Demográfico 2010. Disponível em: http://www.ibge.gov.br/cidadesat/topwindow. htm?1. Acesso em: 7 abr. 2012.

ISIDORI, M.; FERRARA, M.; LAVORGNA, M.; NARDELLI, A.; PARRELLA A. In situ monitoring of urban air in Southern Italy with the Tradescantia micronucleus bioassay and semipermeable membrane devices (SPMDs). Chemosphere, Oxford, v. 52, n. 1, p. 121-6, 2003.

JÚNIOR, J. A. S.; JÚNIOR, J. C. S. S.; OLIVEIRA, J. L.; CERQUEIRA, E. M. M.; MEIRELES, J. R. C. Micronúcleos em tétrades de Tradescantia pallida (Rose) Hunt. cv. purpurea Boom: alterações genéticas decorrentes de poluição aérea urbana. Acta Scientiarum Biological Sciences, Maringá, v. 30, n. 3, p. 295-301, 2008 .

KLUMPP, A.; ANSEL, W.; KLUMPP, G.; FOMIN, A. Um novo conceito de monitoramento e comunicação ambiental: a rede européia para a avaliação da qualidade do ar usando plantas bioindicadoras (EuroBionet). Revista Brasileira de Botânica, São Paulo, v. 24, n. 4, p. 511-518, 2001. 
TEIXEIRA, M. C. V.; BARBÉRIO, A. Biomonitoramento do ar com Tradescantia pallida (Rose) D. R. Hunt var purpurea Boom (Commelinaceae). Ambi-Agua, Taubaté, v. 7, n. 3, p. 279-292, 2012. (http://dx.doi.org/10.4136/ambi-agua.982)

KLUMPP, A. European network for the assessment of air quality by the use of bioindicator plants - Final report In: University of Hohenheim, Germany, 2004. Disponível em: http://ec.europa.eu/environment/life/project/Projects/index.cfm? fuseaction $=$ search.dspPage\&n_proj_id=1050\&docType=pdf. Acesso em: 15 abr. 2011.

KLUMPP, A.; ANSEL, W.; KLUMPP, G.; CALATAYUD, V.; GARREC, J. P.; HE, S.; PEÑUELAS, J.; RIBAS, A.; RO-POULSEN, H.; RASMUSSEN, S.; SANZ, M. J.; VERGNE, P. Tradescantia micronucleus test indicates genotoxic potential of traffic emissions in European cities. Environmental Pollution, Barking, v. 139, n. 3, p. 515-522, 2006.

LISBÔA, M. F.; IGNOTTI, E. Viabilidade polínica de Tradescantia pallida (Rose) D. R. Hunt var. purpurea ocorrente no município de Alta Floresta (Commelinaceae). In: $1^{\text {a }}$ Jornada cientifica de Unemat, Cárceres, Mato Grosso, 2008. Disponível em: http://www.unemat.br/eventos/jornada2008/resumos_conic/Expandido_00764.pdf Acesso em: 3 mar. 2011.

LORENZI, H.; SOUZA, H. M. Plantas Ornamentais do Brasil. Ed. Nova Odessa: Plantarum, p. 1088, 2001.

MA, T. H. Tradescantia micronucleus bioassay and pollen tube chromatid aberration test for in situ monitoring and mutagen screening. Environmental Health Perspectives, Estados Unidos, v. 37, p. 85-90, 1981.

MA, T. H. Tradescantia micronuclei (Trad-MN) test for environmental clastogens. In: Kolber, A. R.; Wong, T. K.; Grant, Lester D.; DeWoskin, Robert S. \& Hughes, J. $\mathrm{T}$. In vitro toxicity testing of environmental agents. Ed. Plenum Publishing Corporation, New York, 1983, p. 1191-214.

MA, T. H.; CABRERA, G. L.; CEBULSKA-WASILEWSKA, A.; CHEN, R.; LOARCA, F.; VANDENBER, A. L.; SALAMONE, M. F. Tradescantia stamen hair mutation bioassay. Mutation Research, Amsterdam, v. 310, n. 2, p. 211-220, 1994.

MAJER, B. J.; LAKY, B.; KNASMÜLLER, S.; KASSIE, F. Use of the Micronucleus Assay with Exfoliated Epithelial Cells as a Biomarker for Monitoring Individuals at Elevated Risk of Genetic Damage and in Chemoprevention Trials. Mutation Research, Amsterdam, v. 489, n. 2-3, p. 147-172, 2001.

MARCILIO, I.; GOUVEIA, N. Quantifying the impact of air pollution on the urban population of Brazil. Caderno de Saúde Pública, Rio de Janeiro, v. 23, n. 4, p. 529-536, 2007.

MARIANI, R. L.; JORGE, M. P. M.; PEREIRA, S. S. Caracterização da qualidade do ar em São José Dos Campos-SP, utilizando Tradescantia pallida (Trad-MCN). Revista Brasileira de Geoquímica, Goiás, v. 22, n. 1, p. 27-33, 2008.

MIELLI, A. C. Avaliação da atividade genotóxica de logo de esgoto tratado do estado de São Paulo com o teste de micronúcleo em células germinativa de Tradescantia (Trad-MN), 2008 Tese (Doutorado em Patologia), Faculdade de Medicina da Universidade de São Paulo, São Paulo. 2008. 
TEIXEIRA, M. C. V.; BARBÉRIO, A. Biomonitoramento do ar com Tradescantia pallida (Rose) D. R. Hunt var purpurea Boom (Commelinaceae). Ambi-Agua, Taubaté, v. 7, n. 3, p. 279-292, 2012. (http://dx.doi.org/10.4136/ambi-agua.982)

MISÍK, M.; MICIETA, K.; SOLENSKÁ, M.; MISÍKOVÁ, K.; PISARCÍKOVÁ, H.; KNASMÜLLER, S. In situ biomonitoring of the genotoxic effects of mixed industrial emissions using the Tradescantia micronucleus and pollen abortion tests with wild life plants: Demonstration of the efficacy of emission controls in an eastern European city. Environmental Pollution, Barking, v. 145, n. 2, p. 459466, 2007.

MOLINA, M. J.; MOLINA, L. T. Megacities and atmospheric pollution. Journal of the Air and Waste Management Association, Pittsburgh, v. 54, n. 6, p. 644-680, 2004.

MONARCA, S.; FERRETI, D.; ZANARDINI, A.; FALISTOCCO, E.; NARDI, G. Monitoring of mutagens in urban air sample. Mutation Research, Amsterdam, v. 426, n. 2, p. 189-192, 1999.

NASCIMENTO, L. F. C.; PEREIRA, L. A. A.; BRAGA, A. L. F.; MÓDOLO, M. C. C.; CARVALHO, J. R. J. A. Efeitos da poluição atmosférica na saúde infantil em São José dos Campos, SP. Revista de Saúde Pública, São Paulo, v. 40, n. 1, p. 77-82, 2006.

OLIVEIRA, D. S.; CRNKOVIC, P. M.; PAGLIUSO, J. D. Avaliação da mutagenicidade causada por poluentes presentes na exaustão de motor diesel por meio de bioindicador vegetal. In: VII Congresso de Ecologia do Brasil, 2005, Caxambú, MG. Disponível em: http://www.seb-ecologia.org.br/viiceb/resumos/ 489a.pdf. Acesso: 25 mai. 2011.

PRAJAPATI, S. K.; TRIPATHI, B. D. Assessing the genotoxicity of urban air pollutants in Varanasi City using Tradescantia micronucleus (Trad-MCN) bioassay. Environment International, Elmsford, v. 34, n. 4, p. 1092-1096, 2008.

RAMIREZ, A.; SALDANHA, P. H. Micronucleus investigation of alcoholic patients with oral carcinomas. Genetics and Molecular Research, Ribeirão Preto, v 1, n. 3, p. 246-260, 2002.

RODRIGUES, G. S.; MA, T. H.; PIMENTEL, D.; WEINSTEIN, L. H.; ICHIKAWA, $\mathrm{S}$. Tradescantia bioassays as monitoring systems for environmental mutagenesis a review. Critical Reviews in Plant Sciences, Boca Raton, v. 16, n. 4, p. 325359, 1997.

SALDIVA, P. H. N.; LICHTENFELS, A. J. F. C.; PAIVA, P. S. O.; BARONE, I. A.; MARTINS, M. A.; MASSAD, E.; PEREIRA, J. C. R.; XAVIER, V. P.; SINGER, J. M.; BÖHM, G. M. Association between air pollution and mortality due to respiratory diseases in children in São Paulo: a preliminary report. Environmental Research, Hauppauge, v. 65, n. 2, p. 218-225, 1994.

SALDIVA, P. H. N.; POPE, C. A.; SCHWARTZ, J.; DOCKEY, D.; LICHTENFELS, A. J. F. C.; SALGE, J. M.; BARONE, I. A.; BÖHM, G. M. Air pollution and mortality in elderly people: a times series in São Paulo. Archives of Environmental Health, Chicago, v. 50, n. 2, p. 159-163, 1995. 
TEIXEIRA, M. C. V.; BARBÉRIO, A. Biomonitoramento do ar com Tradescantia pallida (Rose) D. R. Hunt var purpurea Boom (Commelinaceae). Ambi-Agua, Taubaté, v. 7, n. 3, p. 279-292, 2012. (http://dx.doi.org/10.4136/ambi-agua.982)

SALDIVA, P. H. N.; CLARKE, R. W.; COULL, B. A.; STEARNS, R. C.; LAWRENCE, J.; MURTHY, G. G. K.; DIAZ, E.; KOUTRAKIS, P.; SUH, H.; TSUDA, A.; GODLESKI, J. J. Lung inflammation induced by concentrated ambient air particles is related to particle composition. American Journal of Respiratory and Critical Care Medicine, New York, v. 165, n. 12, p. 16101617, 2002.

SANT'ANNA, E. T. G. Poluição atmosférica urbana na cidade de São Paulo e mutagênese: avaliação de riscos utilizando-se bioindicadores vegetais do gênero Tradescantia. 2003 Tese (Doutorado em Fisiopatologia Experimental), Universidade de São Paulo, São Paulo - SP. 2003.

SAVÓIA, E. J. L. Potencial de Tradescantia pallida cv. Purpurea para biomonitoramento da poluição aérea de Santo André - São Paulo, por meio do bioensaio Trad - MCN e do acúmulo foliar de elementos tóxicos, 2007 Dissertação (Mestrado em Fisiopatologia Experimental), Universidade de São Paulo, São Paulo - SP. 2007.

SEADE - Sistema Estadual de Análise de Dados (Secretaria de Planejamento e Desenvolvimento Regional - Governo do Estado de São Paulo). Informação dos Municípios Paulistas - IMP: Número de indústrias em Taubaté (código da localidade 3554102). Disponível em: http://www.seade.gov.br/produtos/imp/ index.php?page $=$ consulta\&action $=$ var_list $\&$ tema $=1 \&$ tabs $=1 \&$ aba $=$ tabela 1 . Aces so: 08 mai. 2012.

SERRANO-GARCÍA, L.; MONTERO-MONTOYA, R. Micronuclei and chromatid buds are the result of related genotoxic events. Environmental and Molecular Mutagenesis, New York, v. 38, n. 1, p. 38-45, 2001.

SILVA, J. S. Efeitos genotoxicos em tétrades de Tradescantia pallida (Rose) D. R. Hunt Var. purpurea induzidos por poluentes atmosféricos na cidade de Salvador-BA. 2005 Monografia (Graduação em Ciências Biológicas), Universidade Federal de Feira de Santana, Feira de Santana-BA. 2005.

VALVERDE, B. T.; BRANDEBURGO, M. A. M. Ensaio do aborto de pólen aplicado ao biomonitoramento da qualidade do ar da cidade de Uberlândia. In: IX Encontro Interno \& XIII Seminário de Iniciação Cientifica, Universidade Federal de Uberlândia, 2009. Disponível em: https://ss14799.websiteseguro.com/ swge5/seg/cd2009/PDF/IC2009-0146.pdf. Acesso em: 25 mai. 2011.

WILSON, A. M.; SALLOWAY, J. C.; WAKE, C. P.; KELLY, T. Air pollution and the demand for hospital services: a review. Environment International, Elmsford, v. 30, n. 8, p. 1109-1118, 2004.

WHO. Evaluation and use of epidemiological evidence for environmental health risk assessment - Guideline document. In: World Health Organization Regional Office for Europe, Copenhagen, Denmark, 2000. Disponível em: http://www.euro.who.int/_data/assets/pdf_file/0006/74733/E68940.pdf. Acesso em: 4 de jun. 2011.

WHO The effects of air pollution on children's health and development: a review of the evidence. In: World Health Organization Regional Office for Europe, Copenhagen, Denmark, 2005. Disponível em: http://www.euro.who.int/_data/ assets/ pdf_file/0010/74728/E86575.pdf. Acesso em: 4 de jun. 2011. 
TEIXEIRA, M. C. V.; BARBÉRIO, A. Biomonitoramento do ar com Tradescantia pallida (Rose) D. R. Hunt var purpurea Boom (Commelinaceae). Ambi-Agua, Taubaté, v. 7, n. 3, p. 279-292, 2012. (http://dx.doi.org/10.4136/ambi-agua.982)

YANAGI, Y. Estudo da influência do material particulado na incidência e mortalidade por câncer na cidade de São Paulo, 2010 Dissertação (Mestrado em Saúde Ambiental), Faculdade de Saúde Publica da Universidade de São Paulo, São Paulo. 2010. 